\title{
Resilience and Strategies for Increasing the Consistent use of Modern Contraception in the Health District of East Abobo (Southern Côte D'ivoire)
} Akissi Bernadette KOUADIO ${ }^{1}$, Adou Serge Judicaël ANOUA ${ }^{2 *}$

${ }^{1}$ Abobo-East Health District, Ministry of Health and Public Hygiene, Abidjan, Côte d'Ivoire

${ }^{2}$ Department of Anthropology \& Sociology, Alassane Ouattara University, Bouaké, Côte d'Ivoire, BP V18 Bouaké 01

DOI: $10.36347 /$ sjahss.2021.v09i05.003

| Received: 25.03.2021 | Accepted: 05.05.2021 | Published: 11.05.2021

*Corresponding author: Adou Serge Judicaël ANOUA

Abstract

Original Research Article

The rate of contraceptive use in Côte d'Ivoire remains low (23\%), despite the national target of $31 \%$, as family planning services fail to provide sufficient and accurate information about modern contraceptive methods. This study seeks to present the biomedical and socio-cultural obstacles to the consistent use of modern contraception in the health district of East Abobo and propose a mobilisation strategy aimed at promoting modern contraception. It is qualitative and cross-sectional in nature, with both a descriptive and an analytical approach. Research was conducted between November 2020 and February 2021 in three community health centres, at the free mass medical consultations which they held and which covered contraception. The study relied on participatory observation, as well as 34 individual semi-structured interviews with contraception users, the primary study population, and 8 informal interviews with key informers, the secondary study population. The respondents were partly selected through purposive sampling. The data, mostly consisting of comments and expressions of opinions and perceptions, was recorded on a smartphone by the authors and a community health agent. It was subsequently coded, entered into MAXQDA 12, and subjected to a thematic analysis for the purposes of interpretation. It was found that women's reproductive profile, specifically parity, has a $40 \%$ influence on their choice of modern contraceptive methods and their assessment thereof. Religious and cultural beliefs deterred respondents from modern contraception. The community mobilisation proposed in this study relies on intracommunity communication channels, educating community leaders about modern contraception, and governmental intervention through subsidies for contraceptive methods. In order to promote consistent use of modern contraception, it is essential to raise awareness across all social groups of the benefits of contraception for mothers, their children, and the whole community through interactive communication. If these recommendations are implemented, Côte d'Ivoire could reduce its rate of evitable maternal mortality.

Keywords: Resilience, mobilisation strategy, modern contraception, reproductive health, Côte d'Ivoire.

Copyright (C) 2021 The Author(s): This is an open-access article distributed under the terms of the Creative Commons Attribution 4.0 International License (CC BY-NC 4.0) which permits unrestricted use, distribution, and reproduction in any medium for non-commercial use provided the original author and source are credited.

\section{INTRODUCTION}

Contraception refers to the set of methods that are available to a population for preventing conception and thereby controlling family size, avoiding the occurrence of unwanted pregnancies, and increasing the inter-birth interval [1]. Contraceptive methods often involve the use of contraceptive products. In the medical literature, three main categories of contraceptive methods can be discerned: modern contraception, natural contraception, and traditional contraception. Contraception is or has been stigmatized or disallowed in many societies. In the United States, for example, the Comstock Act passed in 1873, which prohibited the circulation of obscene literature and articles, also applied to the dissemination of information about birth control. In order to promote contraceptive methods and family planning and thus reduce the vulnerability of women, various international conferences have been held and recommendations have been published. For instance, the World Population Plan of Action (WPPA) which resulted from the World Population Conference held in Bucharest in 1974 advocated the right to family planning, and the 1978 Declaration of Alma-Ata adopted at the International Conference on Primary Health Care endorsed the inclusion of family planning services in maternal and child healthcare. Family planning refers to the choice to procreate or not and the anticipation and control of the number and time of pregnancies and the inter-birth interval; it is therefore directly linked to contraceptive practices. 
Contraception policies contribute to the reduction of maternal mortality rates within a given population. However, African countries which have adopted such policies in their healthcare system have not yet managed to enforce them within their communities. For family planning programs to be implemented and succeed in African communities, the involvement of traditional and religious authorities by means of community action is indispensable. However, there is at present much reticence with regard to family planning, which conflicts with traditional values and representations of fertility and procreation. Specifically, African cultures generally view a child as an enrichment of its family, whereas Western cultures are more likely to consider it as a source of poverty [2].

In Côte d'Ivoire, maternal and neonatal morbidity and mortality continue to display alarmingly high rates. According to the National Health Development Plan for 2016-2020, the rate of maternal mortality is 614 per 100,000 live births [3]. One of the reasons for this high figure is precisely the low rate of contraceptive use, which gives rise to a high total fertility rate of 4,6 [4]. The government of Côte d'Ivoire, in concert with its partners, has undertaken many efforts to remedy this state of affairs, notably by adopting a national plan regarding family planning services, the implementation of which is coordinated by a monitoring committee comprised of all the key actors involved in the promotion of family planning. This collaborative endeavour has already led to an enhanced national offer of free family planning services and a reorganisation of healthcare units aimed at adapting them to adolescents and young adults, as well as the population as a whole. As a result, family planning services are offered in $98 \%$ of all public and private healthcare facilities. The target for modern contraception, which was fixed at 600,000 users in 2017, has been raised to 780,000 for 2020. This corresponds to an increase of about 30\% [5]. However, at this date, a rate of contraceptive use of $23 \%$ was calculated, which was below the national target of $31 \%$. This failure to reach the target was recorded in almost all of the health districts of Côte d'Ivoire, including that of East Abobo, in the health region of Abidjan 1, where the rate of contraceptive use went up from $20.8 \%$ in 2017 to $22.6 \%$ in 2018. In 2020, the rate was still a mere $10 \%$ in the health district of East Abobo, according to its annual activity report. In order to improve the rate of contraceptive use in this health district, consultations have been organised with nongovernmental organisations such as the Agence Ivoirienne de Marketing Social (Ivorian Agency for Social Marketing, AIMAS), Population Services International (PSI), and The Challenge Initiative (TCI).

Many studies have so far been devoted to the identification of the social determinants of non-use of modern contraceptive methods. The results of these studies have shown that resistance to modern contraceptive methods is rooted in social representations and perceptions relating to fertility and procreation. This justifies the socio-anthropological theoretical framework that has been adopted in the present study. In the following, the determinants of nonuse of modern contraceptive methods in the health district of East Abobo will be presented. Specifically, the biomedical and socio-cultural obstacles that deter the community from using modern contraceptive methods will be elucidated. Subsequently, a mobilisation strategy aimed at promoting modern contraceptive methods will be laid out.

\section{MATERIALS AND METHODS Scope of the study}

The health district of East Abobo is the larger of the two that comprise the Ivorian commune of Abobo. It is bordered by the health district of West Abobo to the West, the health district of Ayama to the North, the health district of Cocody-Bingerville to the East, and the health district of Adjamé-PlateauAttécoubé to the South. It has a surface area of $67 \mathrm{~km}^{2}$ and in 2019, its population consisted of 703,621 inhabitants. There are 42 healthcare facilities located within this health district, 12 of which are public and 30 private. For the purposes of this study, three urban community healthcare centres which provide family planning services were selected, namely Formation Sanitaire Urbaine Communautaire d'Abobo Avocatier, Formation Sanitaire Urbaine Communautaire d'Abobo Baoulé and Centre de Santé Urbain Communautaire d'Abobo Kennedy Clouetcha. These three healthcare centres were considered relevant to the study because they are community-based and because they have recorded a substantial number of defaulters, defined as users of contraceptive methods who still have not visited three months after the recommended date, as well as many users who have definitively stopped receiving family planning services and have accordingly been withdrawn from the follow-up cohort. The concept of resilience in contraceptive use was also taken into account in this study, considering that many women display a resistance to modern contraceptive methods or have reservations which might deter them from consistent contraceptive use. Such negative attitudes toward modern contraceptive methods stem from socio-cultural beliefs and values. The mobilisation strategy proposed in this study is based on community action aimed at bringing about changes in women's behaviours in relation to modern contraception services.

\section{Study Population}

Interview guides were drafted and distributed to women who had already used contraceptives at some point and had frequented the three health centres; these were defined as the primary study population. They were chosen because of the knowledge that they already had of certain contraceptive methods. Additional interviews were conducted with a secondary study 
population, which consisted of the coordinator for reproductive health and family planning of the health district of East Abobo, three midwives, a representative of each of the three aforementioned NGOs in the health district, and the community health agents of the three health centres. The two study populations are presented in greater detail in Tables 1 and 2.

Table-1: Overview of the respondents comprising the primary study population

\begin{tabular}{|c|c|c|}
\hline Characteristics of the respondents & Interviews & $\%$ \\
\hline \multicolumn{3}{|l|}{ Religion } \\
\hline Muslim & 23 & 67.6 \\
\hline Christian & 11 & 32.4 \\
\hline \multicolumn{3}{|l|}{ Parity } \\
\hline Multiparas & 12 & 35.3 \\
\hline Pauciparas & 15 & 44.1 \\
\hline Nulliparas & 01 & 2.9 \\
\hline Primiparas & 06 & 17.7 \\
\hline \multicolumn{3}{|l|}{ Level of education } \\
\hline Educated & 29 & 85.3 \\
\hline Uneducated & 05 & 14.7 \\
\hline \multicolumn{3}{|l|}{ Marital status } \\
\hline Married & 25 & 73.5 \\
\hline Unmarried & 09 & 26.5 \\
\hline \multicolumn{3}{|l|}{ Occupation } \\
\hline Housewife & 08 & 23.6 \\
\hline Trader & 24 & 70.6 \\
\hline Apprentice & 01 & 2.9 \\
\hline Student & 01 & 2.9 \\
\hline \multicolumn{3}{|l|}{ Ethnicity } \\
\hline Mandinka & 14 & 41.1 \\
\hline Akan & 10 & 29.4 \\
\hline Kru & 03 & 8.9 \\
\hline Burkinabe & 07 & 20.6 \\
\hline \multicolumn{3}{|l|}{ Age range } \\
\hline 21 to 25 years old & 02 & 5.9 \\
\hline 26 to 49 years old & 32 & 94.1 \\
\hline
\end{tabular}

Source: $2020-2021$ field research

Table-2: Overview of the respondents comprising the secondary study population

\begin{tabular}{|ll|}
\hline Respondents & Interviews \\
\hline District coordinator & 01 \\
\hline Midwives & 03 \\
\hline Partners (AIMAS, TCI, PSI, AIBEF) & 04 \\
\hline
\end{tabular}

Source: 2020 field research

\section{Study type and sampling technique}

The present study is cross-sectional in nature and has a descriptive and analytical aim. The results of the research have been described and interpreted qualitatively. The techniques chosen for the research were participatory observation and interviewing. More specifically, following preliminary observation during mass consultations, 34 semi-structured interviews based on interview guides were conducted between the months of November 2020 and February 2021 with the primary study population, and a further 8 informal interviews were conducted with the secondary study population. The criterion for inclusion in the study was being a woman who had used different contraceptive methods on one or more occasions. The sampling technique was partly purposive.

\section{Data collection}

Data was collected by the authors with the help of a community health agent. Most of the data from the primary study population was gathered at the mass consultations organised by the three NGOs (AIMAS, TCI and PSI) between the months of December 2020 and February 2021. As for the secondary study population of the study, they had been interviewed separately between September and November 2020. These preliminary interviews with key were conducted earlier so that the difficulties encountered by the NGOs 
in their interventions could be brought to light. The Departmental Health Director of the health district of East Abobo authorised the study and informed consent was obtained from all members of the primary study population before they were interviewed at the three health centres. Moreover, appropriate steps were taken to guarantee the confidentiality of the data and thus protect respondents' privacy. The interviews had a duration of between 35 and 40 minutes and they were recorded with the help of a smartphone.

\section{Data processing and analysis}

The recorded data, which for the most part consisted of informal comments and expressions of opinions and perceptions, was transcribed and subsequently processed and subjected to a combination of structural and thematic analysis, for the purposes of interpretation and so that more nuanced information could be gleaned from the interviews. The thematic analysis was facilitated by the data analysis software known as MAXQDA, version 12.

\section{RESULTS}

The analysis of the data led to the identification of two main categories of factors relevant to the consistent use of modern contraceptive services in the health district of East Abobo and the mobilisation strategy proposed in this study, namely biomedical and socio-cultural ones.

Biomedical symptoms and conceptions as obstacles to the consistent use of modern contraceptive services

\section{Contraceptive methods}

An overview of modern contraceptive methods and products on offer in Côte d'Ivoire is shown in Table 3 below, reproduced from the 2018 National Program for Maternal and Child Health (PNSME), whereas Table 4 presents the categories of contraceptive methods used by the primary study population, according to information obtained through the interviews.

Table-3: Overview of modern contraceptive methods offered in Côte d'Ivoire

\begin{tabular}{|l|l|}
\hline Category & \multicolumn{2}{l|}{ Method } \\
\hline \multirow{2}{*}{ Long-term contraceptive methods } & Tubal ligation \\
\cline { 2 - 2 } & Vasectomy \\
\hline \multirow{2}{*}{ Intra-uterine devices (IUD) } & Copper T380A IUD \\
\cline { 2 - 2 } Implants & LNG-IUS \\
\cline { 2 - 2 } & Implanon \\
\cline { 2 - 2 } Short-term contraceptive methods & Sino-implant \\
\hline \multirow{4}{*}{ Injectable contraceptives } & Depo Provera (DMPA) \\
\cline { 2 - 2 } & Noristerat (NET-EN) \\
\cline { 2 - 2 } & Lunelle \\
\cline { 2 - 2 } & Sayana Press \\
\hline \multirow{2}{*}{ Pills } & Combined oral contraceptive (COC) \\
\cline { 2 - 2 } & Progestogen-only pill (POP) \\
\hline \multirow{2}{*}{ Condoms } & Male condom \\
\cline { 2 - 2 } & Female condom \\
\hline \multirow{3}{*}{ Other } & Standard days method (SDM) \\
\cline { 2 - 2 } & Diaphragm \\
\cline { 2 - 2 } & Spermicide \\
\hline Emergency contraceptive methods & \\
\hline
\end{tabular}

Source: PNSME 2018

Table-4: Contraceptive methods that had been used by the respondents

\begin{tabular}{|l|}
\hline IUD (effective for a period of 10 years) \\
\hline Implants (effective for a period of 3 to 5 years) \\
\hline Injections (effective for a period of 2 to 3 months) \\
\hline Pills (effective for a period of 1 month) \\
\hline
\end{tabular}

Source: $2020-2021$ field research

The primary study population was familiar with and used two long-acting reversible contraceptive methods, IUDs and implants (specifically Jadelle and Implanon NXT), as well as two short-term methods, 
injections (Depo Provera) and oral contraceptives (pills). The women chose between these different methods based on convenience as well as their reproductive profile.

\section{Choice of contraceptive method and parity}

Table 5 below divides the respondents of the primary study population into four parity categories, multiparas, pauciparas, primiparas and nulliparas, and for each of the four categories of contraceptive methods, it shows what proportion of women used it.

Table 5: Modern contraceptive methods by parity category

\begin{tabular}{|l|ll|ll|ll|ll|}
\hline \multirow{2}{*}{$\begin{array}{l}\text { Method } \\
\text { Parity }\end{array}$} & IUD & \multicolumn{2}{|l|}{ Implants } & \multicolumn{2}{l|}{ Injections } & Pills \\
\cline { 2 - 10 } & No. & \% & No. & \% & No. & \% & No. & \% \\
\hline Multiparas & 00 & 0 & 05 & 41.6 & 04 & 33.3 & 04 & 33.3 \\
\hline Pauciparas & 01 & 6.6 & 07 & 46.6 & 03 & 20 & 07 & 46.6 \\
\hline Primiparas & 00 & 0 & 05 & 83.3 & 01 & 16.6 & 00 & 0 \\
\hline Nulliparas & 00 & 0 & 01 & 100 & 00 & 0 & 00 & 0 \\
\hline
\end{tabular}

Source: 2021 field research

It can be seen that implants were the most widespread contraceptive method among the members of the primary study population. The proportion of women who relied on implants ranged from $100 \%$ in the category of nulliparas to $83 \%$ for primiparas, $46.6 \%$ for pauciparas, and $41.6 \%$ for multiparas. The second most popular contraceptive method turned out to be pills, used by $46.6 \%$ of pauciparas and $33.3 \%$ of multiparas. It should be noted that parity does not constitute a contraindication to any individual contraceptive method.

Factors which deterred the respondents from modern contraceptive methods

Table 6: Factors which deterred the respondents from modern contraceptive methods

\begin{tabular}{|l|l|}
\hline Contraceptive method & Reasons for not using it \\
\hline \multirow{4}{*}{ Pills } & Forgetting to take the pill at the right hour \\
\cline { 2 - 2 } & Headaches \\
\cline { 2 - 2 } & Nausea \\
\cline { 2 - 2 } & Vomiting \\
\hline \multirow{5}{*}{ Injections } & Pain at the injection site \\
\cline { 2 - 2 } & Amenorrhoea \\
\cline { 2 - 2 } & Spotting \\
\cline { 2 - 2 } & Excess weight gain \\
\cline { 2 - 2 } & Sterility \\
\cline { 2 - 2 } & Reduced sex drive \\
\hline \multirow{5}{*}{ Implants } & Amenorrhoea \\
\cline { 2 - 2 } & Fear that the implant might disappear inside \\
the body
\end{tabular}

Source: 2021 field research

Table 6 clearly shows that the main reason for which the respondents were discouraged from using modern contraceptive methods was the range of adverse physiological side effects that they had experienced, such as headaches or spotting, but also rumours and preconceptions about the dangers of modern contraceptive methods, whence the fear that the implant might disappear inside the body or of being unable to have children in future.
Socio-cultural representations of children as obstacles to the consistent use of modern contraceptive methods

Perception of children in the Mandinka culture

The "right to procreate" is the argument that was advanced with the greatest insistence by the Mandinka respondents in the interviews. Many of these respondents contended that conception is a fundamental and inalienable right that all women have and they considered recourse to modern contraceptive practices to be a direct violation of this right. They added that children are a "gift from God" and described them as 
"precious beings". One respondent claimed that by using modern contraceptive methods, one would run the risk of incurring "the wrath of God". She was also of opinion that modern contraceptive products are at the root of the infertility that afflicts many young couples in the present day. Such perceptions evidently have a detrimental effect on the promotion of modern contraceptive methods in Côte d'Ivoire.

\section{Perception of children in the Akan culture}

Most of the respondents from the Akan ethnic group belonged to the Baoulé and Ébrié subgroups. They also considered children to be "gifts from God" and described them as being the cornerstone of all human relations. One of the Baoule respondents reported that in view of the significance of children, various rituals are performed in order to help a young pubescent woman to conceive if she has failed to do so. The rituals in question are ways of "worshipping the gods of water and the woods" and also involve compliance with a set of dietary prohibitions. After having had such cultural representations inculcated in them, it is unsurprising that women should be reluctant to avail themselves of modern contraceptive methods. They might even be pressured to comply with traditional beliefs and values by their relatives, as in the case of one respondent who related that her mother-inlaw had demanded that she stop using contraceptive products so that she would not bring the "wrath of the gods" upon herself by preventing a pregnancy. The same respondent likened contraceptive products to abortifacients. Another respondent even argued that preventing a pregnancy is in itself a sort of abortion, one which she referred to as "modern abortion". On the whole, it appears that there is confusion between abortion and contraception and that contraceptive products are thought by some to serve to induce an abortion. This phenomenon was discussed at length by one of the midwives who was interviewed. She explained that some pregnant women would turn up at the health centres in order to have contraceptive products administered to them, in the hope that this would enable them to abort.

\section{Perception of children in the Burkinabe culture}

The Burkinabe respondents also extolled children, claiming that they were "at the heart of everything". According to one of the respondents, a couple with a child would have a $90 \%$ greater chance of survival than a couple without any children. Along the same lines, another respondent revealed that after getting married and failing to conceive for ten years, her husband found himself another wife. These testimonies illustrate the fundamental importance that children have in the family. Thus, it transpires that aversion to modern contraceptive methods is a consequence of sociocultural beliefs and representations of children upheld by individuals or communities in Côte d'Ivoire.

\section{Reproductive factors deterring the respondents from modern contraceptive methods}

The respondents also justified their avoidance of modern contraceptive methods by invoking reproductive factors. Their primary concern, which they expressed at the mass consultations, was whether they would ever be able to have children again if they used a particular contraceptive product. It was repeatedly observed that they would avoid the contraceptive services and that once they had been offered a particular product, they would raise some objection to its provenance or come up with some other excuse. One respondent declined contraception on the grounds that her husband had instructed her to refuse any gratuitous product offered to her in a healthcare centre. However, the same respondent took oral contraceptives. She was hesitant because she was afraid that the use of contraception might prevent her from having a child in future and she had reservations about the medical services offered at the event because it was a free mass consultation. Another respondent who was a multipara complained of a reduced sex drive under the influence of contraceptive methods. For the sake of the quality of her life at home, she preferred to take the time to think about which contraceptive method would be the most suitable for her, regardless of all the explanations that a midwife had provided her with. Similar behaviour was observed in certain pauciparous women, who remained reluctant about using modern contraceptive methods even after having been counselled, because of their prejudices, shared with their social milieu. The majority of these prejudices directly concerned fertility and procreation.

\section{Outline of a mobilisation strategy aimed at promoting modern contraceptive methods}

The factors relevant to the mobilisation strategy aimed at promoting modern contraceptive methods that is developed in this study are the empirically observed problems, their underlying causes, the actions proposed to counter them, and the actors that would need to be mobilised within the community, as shown in Table 7 below. 
Table-7: Outline of a mobilisation strategy aimed at promoting modern contraceptive methods

\begin{tabular}{|c|c|c|c|}
\hline Observed problem & Underlying causes & Proposed actions & Actors involved \\
\hline $\begin{array}{l}\text { Lack of sufficient and } \\
\text { accurate information } \\
\text { about modern } \\
\text { contraceptive methods }\end{array}$ & $\begin{array}{l}\text { - Traditional religious and } \\
\text { cultural beliefs and values } \\
\text { - Rumours } \\
\text { - Prejudices } \\
\text { - Lack of spousal } \\
\text { involvement } \\
\text { - Adverse side effects }\end{array}$ & $\begin{array}{l}\text { - Local radio broadcasts that } \\
\text { would provide detailed } \\
\text { information about } \\
\text { contraceptive methods } \\
\text { - Training spiritual leaders to } \\
\text { teach contraceptive methods in } \\
\text { places of worship } \\
\text { - Disseminating information } \\
\text { about contraceptive methods } \\
\text { through communication } \\
\text { networks in public spaces like } \\
\text { markets and places of worship } \\
\text { - Inviting spouses to attend } \\
\text { family planning sessions }\end{array}$ & $\begin{array}{l}\text { - Healthcare workers } \\
\text { - Women's associations } \\
\text { - Spiritual leaders } \\
\text { - Community health } \\
\text { agents } \\
\text { - Government of Côte } \\
\text { d'Ivoire } \\
\text { - National and } \\
\text { international health } \\
\text { partners }\end{array}$ \\
\hline $\begin{array}{l}\text { Excessive prices } \\
(3,000-8,000 \text { XOF) of } \\
\text { long-acting methods } \\
\text { (IUDs and implants) } \\
\text { in health centres }\end{array}$ & - Lack of exemption policies & $\begin{array}{l}\text { - Making all modern } \\
\text { contraceptive methods } \\
\text { financially accessible }\end{array}$ & $\begin{array}{l}\text { - Government of Côte } \\
\text { d'Ivoire } \\
\text { - National and } \\
\text { international health } \\
\text { partners }\end{array}$ \\
\hline
\end{tabular}

Source: 2021 field research

The analysis of the data revealed two major problems that discourage the use of modern contraceptive methods, namely the lack of sufficient and accurate information about modern contraceptive methods and the excessive prices of long-acting methods such as IUDs and implants. Based on the interviews conducted with the respondents, the underlying causes of these problems were identified as traditional religious and cultural beliefs and values, rumors and prejudices of the sort presented in Table 6 , a lack of spousal involvement, adverse side effects of the sort presented in Table 6, and a lack of exemption policies. With the problems and their underlying causes as a starting point, measures which could help to resolve them were suggested, in collaboration with the respondents. As insufficient information gives rise to uncertainty and resistance towards modern contraceptive methods, the respondents agreed that disseminating more information through mass media such as local radio stations, getting community leaders (for example, in women's associations or places of worship such as mosques and churches) to teach about modern contraceptive methods, encouraging more mass communication about contraceptive methods in public spaces, and involving husbands could be effective actions to promote modern contraceptive methods.

\section{DISCUSSION}

The concept of resilience refers to the ability that individuals, households and communities have to resist external shocks. It implies adaptation and recovery in response to any disruptive change or transformation, social or other, in a way that reduces individuals' vulnerability [6]. Bremner, Patterson and Yavinsky have explained that family planning and consequently contraceptive methods can increase the resilience of a given community, but this correlation could not be examined within the scope of this study, as the gathered data did not provide indications as to the resilience of the communities of the respondents, nor was any transformation identified in the face of which they could display a certain degree of resilience. Instead, the data drew attention to the range of biomedical and socio-cultural factors that constitute obstacles to the consistent use of modern contraceptive methods in the health district of East Abobo.

The use of modern contraceptive methods was studied in relation to parity and it was found that certain types of contraceptive methods were more commonly used in some parity categories than in others. Firstly, implants were the dominant contraceptive method among primiparas (used by $83.3 \%$ ) and the only one that was used by the single multipara (100\%). Secondly, oral contraceptives were one of the most commonly used methods for the category of pauciparas (46.6\%), tied with contraceptive implants, and they were also used by multiparas (33.3\%), but not by any of the primiparas or nulliparas. As far as injectable products are concerned, it is again primarily multiparas and pauciparas who made use of them $33.3 \%$ and $20 \%$ respectively). The low rate of use of oral contraceptives can be attributed to the problems that respondents had experienced with them, which included forgetting to take pills at the right hour and vomiting. A study on contraceptive methods by Fonquerne reveals that in the Western world, oral contraceptives remain the most common contraceptive method despite the various ailments that users experience because of them [7]. Regarding the contraceptive preferences of the nulliparas and primiparas interviewed for the present study, the fact that they were less inclined to procreate 
can explain their tendency to use long-acting contraceptive methods. Multiparas' and pauciparas' use of injectable products is in turn ascribable to the fact that they only wished to forestall their next pregnancy temporarily. In the medical literature, it has been pointed out that after cessation of the use of injectable contraceptives, the return to full fertility can take between two and five months [8]. It follows that women who only wish to delay their next pregnancy briefly might find this contraceptive method ill-suited to their needs. However, women who have already had two or more children tend to want to rest for a longer period before their next pregnancy. Such considerations show why parity is a decisive factor in the choice of contraceptive methods.

In addition to the side-effects brought on by modern contraceptive methods, the respondents were averse to them because of rumours they had heard and prejudices that they harboured, including the fear that the implant might disappear inside the body or of being unable to have children in future. Regarding the latter apprehension, in a study on the determinants of non-use of contraceptive methods in northern Cameroon, Zra affirms that in Africa in general, a profound, atavistic dread of infertility has existed since times immemorial, and that as a result, couples and their in-laws tend to go to great lengths to spare the family, and the bride in particular, the disgrace of remaining childless [2]. Therefore, the significance of fear as an obstacle to the adoption of modern contraceptive methods cannot be understated. Another study by Chiesa-Moutandou et al., on the subject of contraceptive behaviour in Gabon, also addresses fear of infertility, attributing it to prejudice and misinformation [9]. Fear and uncertainty with respect to IUDs and implants in particular have been discussed by Clochey in her doctoral dissertation on the subject of the difficulties and methods of inserting IUDs in Lorraine, France [10]. Another reason for refraining from contraceptives that the present study identified through the interviews was erroneously equating them with abortifacient medication.

The adverse side effects of modern contraceptive methods signaled by the respondents of the present study are in keeping with Nomenjanahary's findings, who claims that such side effects could hinder the spread of modern contraceptive methods [11]. Koné also acknowledges that the occurrence of adverse side effects during the use of a given contraceptive method could lead to the total abandonment of the latter [1]. Lastly, Anoua points out that the manifestation of adverse side effects is a source of great disquiet within households [12]. All of these findings show that adverse side effects, as well as potential users' parity, must be taken into account in the drafting of policies and planning of initiatives aimed at promoting the consistent use of modern contraceptive methods.
Religious and cultural beliefs and values also impede the consistent use of modern contraceptive methods. The respondents who were interviewed came from communities which fall within three large ethnic groups, namely Mandinka, represented by $41.1 \%$ of the respondents, Akan (29.4\%), and Burkinabe (20.6\%). Due to this ethnic diversity, the respondents raised different cultural objections to the use of modern contraceptive methods. Among the Mandinka, contraception was viewed as a violation of the fundamental right to procreate, whereas conception was considered to guarantee a family stability. Furthermore, from a religious point of view, children were seen as gifts from God; consequently, the adoption of contraceptive methods would compromise religious principles and is viewed negatively. Children are also seen as divine gifts by the Akan, both by the Baoulé and the Ébrié, who furthermore believe that children are the cornerstone of all human relations. Finally, among the Burkinabe, children are considered essential in a marriage, which would consequently be jeopardised by contraceptive practices. Odile discusses the presence of similar beliefs and values among the Dyula, where bringing a child into the world is a woman's only way of attaining a respectable social standing [13]. Additionally, Jobin's dissertation on contraceptive methods points out that fertility is culturally construed as female responsibility and that as a result, a couple's reproductive problems are always to be blamed on the woman [14]. The pressure that such beliefs place on women further deters them from using contraceptive methods. Misconceptions of this sort account for the complaints on the part of the interviewed women regarding the lack of adequate information about contraceptive methods. In their study on contraceptive methods in Ghana, Aryeetey et al. similarly note that interventions are necessary to counter the sources of misconceptions about contraceptive methods and improve the provision of contraceptive services [15].

The mobilisation strategy aimed at promoting the use of modern contraceptive methods that was agreed upon by the respondents of the present study primarily addresses the lack of sufficient and accurate information about contraceptives, which so many of the women reported and which leaves room for the spread and entrenchment of rumours and prejudices. On this subject, Ntambue et al. argue that as long as the information provided regarding the contraceptive methods on offer is superficial or fails to refute all of the population's possible arguments against contraceptive methods, there is a risk that women will continue to steer clear of contraceptive methods and cling to their misguided beliefs [16]. For ChiesaMoutandou et al. too, the absence of convincing information about modern contraceptive methods is an important factor which limits its use and consequently hinders the effective regulation of pregnancies in a population [9]. In order to remedy the current state of affairs, the respondents of the present study called for 
the involvement of husbands in the promotion of modern contraceptive methods. They believed that the exclusion of the male sex was to a large extent responsible for the persistently low rates of contraceptive use. Ideally, discussions should be encouraged between spouses so that husbands can gain more awareness of contraceptive practices [17]. The second major problem that was identified for the mobilisation strategy were the high prices of longacting contraceptive methods (ranging from 3000 to 8000 XOF), which make them unaffordable for many women. Zra notes that in Cameroon too, the prices of modern contraceptive methods extinguish any desire that the poor might have to use it to regulate their fertility [2].

\section{CONCLUSION}

Targeted interventions are needed to promote the adoption and subsequently the consistent use of modern contraceptive methods in Côte d'Ivoire and in the health district of East Abobo in particular. At present, there is already a considerable demand for contraceptive methods, but various obstacles such as adverse side effects or traditional religious and cultural beliefs and values, which are correlated with ethnicity, hinder its integration into family planning services and its use and spread more broadly. More efficient communication and raising awareness within communities is necessary for wider and sustainable use of modern contraceptive methods in Côte d'Ivoire, which would in turn increase community resilience and reduce evitable maternal mortality.

\section{ACKNOWLEDGEMENTS}

We would like to thank the Departmental Health Director of the health district of East Abobo and the heads of the healthcare centres for allowing us to go through with our field research. We are likewise grateful to the respondents for their availability and willingness to participate in our interviews.

\section{REFERENCES}

1. Koné A. Facteurs associés à l'utilisation des méthodes contraceptives modernes par les femmes de 15-49 ans dans le District Sanitaire Abobo-Est : Cas de la FSU-COM Avocatier [Factors associated with the use of modern contraceptive methods by women aged 15 to 48 in the health district of East Abobo: the case of the urban healthcare centre FSU-COM Avocatier]. INFAS, Abidjan, Côte d'Ivoire. 2020; 81-97.

2. Zra I. Facteurs associés à la non-utilisation de la contraception moderne chez les femmes en union dans la partie septentrionale du Cameroun [Factors associated with non-use of modern contraception among married women in northern Cameroon] [Internet]. Université de Yaoundé II, Cameroon. 2008 Aug [cited 2021 Apr 7]; 21-101. Available from: https://ireda.ceped.org/inventaire/ressources/zra_iss a_2008.pdf

3. Ministère de la santé et de l'hygiène publique. Plan national de développement sanitaire 2016-2020 [National Health Development Plan 2016-2020] [Internet]. Abidjan, Côte d'Ivoire. 2016 [cited 2021 Apr 7]; 88 p. Available from: https://www.childrenandaids.org/sites/default/files/ 2017-11/pnds_2016-2020.pdf

4. Ministère de la santé et de la lutte contre le sida, Institut national de la statistique, ICF international. Enquête Démographique et de Santé et à Indicateurs Multiples de Côte d'Ivoire 2011-2012 : Rapport préliminaire [Multiple-indicator demographic and healthcare survey, Côte d'Ivoire, 2011-2012: preliminary report] [Internet]. Calverton, Maryland, USA. 2012 [cited 2021 Apr 7]; 561 p. Available from: https://www.dhsprogram.com/pubs/pdf/FR272/FR2 72.pdf

5. [5]. Ministère de la santé et de l'hygiène publique. Rapport annuel de la situation sanitaire 2018 [Annual health situation report 2018] [Internet]. Abidjan, Côte d'Ivoire. 2018 [cited 2021 Apr 7]; 407 p. Available from: http://www.snisdiis.com/wpcontent/uploads/2020/08/RASS-2018-VFn.pdf

6. Bremner J, Patterson K, Yavinsky R. Vers une plus grande résilience grâce à la planification familiale : une approche transformatrice qui s'adresse aux femmes, aux familles et aux collectivités [Towards greater resilience through family planning: a transformational approach aimed at women, families and communities] [Internet]. Population Reference Bureau, Washington D.C., USA. 2015 [cited 2020 Sep 3]; 7 p. Available from: http://www.prb.org/pdf15/prb-policy-brief-sahelresilience-french-2015.pdf

7. Fonquerne L. À qui faire avaler la pilule? [Who needs to have their pill sweetened?] Émulations Revue de sciences sociales. 2020; (35-36): 65-79.

8. Lalaina MM. Utilisation des méthodes contraceptives modernes au CSBII Cité des Assureurs ITAOSY [Use of modern contraceptive methods in the level-2 basic health centre Cité des Assureurs ITAOSY] [Internet]. Université d'Antananarivo, Madagascar. 2003 [cited 2020 Sep 3]; 1-57. Available from: http://biblio.univantananarivo.mg/pdfs/randriambololomanana.pdf.

9. Chiesa-Moutandou S, Wantou GT. Le comportement contraceptif des Gabonaises. Les méthodes modernes: Faible taux d'utilisation et déficit d'information. [Contraceptive practices among Gabonese women. Modern methods: low rates of use and information deficit]. Médecine d'Afrique Noire. 2001; 48(5): 191-198.

10. Clochey J. Difficultés et stratégies mises en place lors de la pose d'un DIU : étude qualitative auprès de médecins généralistes et de gynécologues en Lorraine [Difficulties and methods of inserting 
IUDs: qualitative study conduct on GPs and gynaecologists in Lorraine] [Internet]. Université de Lorraine, France. 2015 [cited 2020 Sep 3]; 164 p. Available from: https://hal.univ-lorraine.fr/hal01733812/document

11. Nomenjanahary V. Prévalence des effets secondaires des contraceptifs modernes au CSB2 d'Amparafaravola [Incidence of side effects of modern contraceptives in the level- 2 basic health centre of Amparafaravola] [Internet]. Université d'Antananarivo, Madagascar. 2007 [cited 2020 Sep 3]; 88 p. Available from: http://biblio.univantananarivo.mg/pdfs/vololoniaina_med_doc_07.p df

12. Anoua ASJ. Problématique de l'usage des contraceptifs hormonaux en milieu rural Gwa de Domlon Côte d'Ivoire [Problems of hormonal contraceptives among the rural Gwa community of Domlon, Côte d'Ivoire]. European Scientific Journal. 2016; 12(32): 298-313.

13. Journet $\mathrm{O}$. La quête de l'enfant [Seeking the child]. Journal des africanistes. 1981, 51(1-2): 97-115.

14. Jobin F. Discours, pratiques et représentations autour de la contraception médicalisée au Bénin : regard anthropologique sur la fréquentation d'une clinique privée à Abomey [Discourse, practices and representations regarding medical contraception in Benin: an anthropological perspective on a private clinic in Abomey] [Internet]. Université de Neuchâtel, Switzerland. 2008 [cited 2020 Sep 3];
135 p. Available from: https://doc.rero.ch/record/10681/files/mem_JobinF. pdf

15. Aryeetey R, Kotoh AM, Hindin MJ. Knowledge, perceptions and ever use of modern contraception among women in the $\mathrm{Ga}$ East District, Ghana. African Journal of Reproductive Health. 2010; 14(4): 27-32.

16. Ntambue AM, Tshiala RN, Malonga FK, Ilunga TM, Kamonayi JM, Kazadi ST, Donnen P. Utilisation des méthodes contraceptives modernes en République Démocratique du Congo : prévalence et barrières dans la zone de santé de Dibindi à Mbuji-Mayi [Modern contraceptive methods in the Democratic Republic of the Congo: rate of use and obstacles in the health region of Dibindi in the city of Mbuji-Mayi]. The Pan African Medical Journal. 2017; 26:199.

17. Konditamde A. Déterminants de l'attitude des hommes face à la pratique de la contraception moderne des femmes en milieu rural burkinabè [Determinants of men's attitudes toward modern contraception used by woman among the rural Burkinabe] [Internet]. Institut de formation et de recherche interdisciplinaires en sciences de la santé et de l'éducation, Burkina Faso. 2017 [cited 2020 Sep 3]; 138 p. Available from: http://www.ifrisbf.org/wp-content/uploads/2018/12/2-

KONDITAMDE_-contraception-moderne-desfemmes_attitudes-des-hommes.pdf 